\title{
Selenium treatment significantly inhibits tumor necrosis factor- $\alpha$-induced cell death and tau hyperphosphorylation in neuroblastoma cells
}

\author{
YOUNG JU LEE, JI EUN KIM, MOON HWA KWAK, JUN GO, SEUNG YUN YANG, HYEOG SOONG KWON, \\ BYOUNG CHUL KIM, JOO MAN KIM and DAE YOUN HWANG
}

College of Natural Resources and Life Science/Life and Industry Convergence Research Institute, Pusan National University, Miryang-si, Gyeongsangnam-do 627-706, Republic of Korea

Received November 15, 2013; Accepted May 2, 2014

DOI: $10.3892 / \mathrm{mmr} .2014 .2442$

\begin{abstract}
The hyperphosphorylation of the protein tau disrupts its normal function on regulating axonal transport and leads to the accumulation of neurofibrillary tangles (NFT), which are involved in the pathogenesis of Alzheimer's disease (AD). This study was performed to investigate whether sodium selenite may inhibit the hyperphosphorylation of tau induced by treatment with tumor necrosis factor- $\alpha$ (TNF- $\alpha$ ). For this purpose, we studied the changes in cell viability, tau phosphorylation and activity of tau kinases in TNF- $\alpha+$ selenite-treated neuroblastoma cells. Cell viability was significantly recovered in the group cotreated with TNF- $\alpha$ and $5 \mu \mathrm{M}$ selenite for $24 \mathrm{~h}$, but not in the groups treated with TNF- $\alpha$ and lower concentrations of selenite. Tau phosphorylation was significantly higher in the group treated with TNF- $\alpha+$ vehicle (instead of selenite) compared to the non-treated group. However, in the TNF- $\alpha+$ selenite-treated group, the total phosphorylation level of tau protein at the Ser404 site was significantly reduced compared to the TNF- $\alpha+$ vehicle group, although western blot analysis revealed one band of increased intensity in the p-tau sample, corresponding to a phosphorylated tau isoform of $65-70 \mathrm{kDa}$. In addition, sodium selenite treatment led to a significant recovery in the immunofluorescence intensity of the p-tau protein in the cytoplasm and nucleus and in the apoptotic rate of neuroblastoma cells stained with the p-tau antibody and 4',6-diamidino-2-phenylindole (DAPI). The phosphorylation of two protein kinases responsible for phosphorylation of tau, glycogen synthase kinase $3 \beta$ (GSK-3 $\beta$ ) and Akt, also known as protein kinase B, was markedly
\end{abstract}

Correspondence to: Professor Dae Youn Hwang, College of Natural Resources and Life Science/Life and Industry Convergence Research Institute, Pusan National University, 50 Cheonghak-ri, Samnangjin-eup, Miryang-si, Gyeongsangnam-do 627-706, Republic of Korea

E-mail: dyhwang@pusan.ac.kr

Key words: selenium, TNF- $\alpha$, tau hyperphosphorylation, GSK-3 $\beta$, Akt, Alzheimer's disease decreased in the TNF- $\alpha+$ selenite-treated group relative to the TNF- $\alpha+$ vehicle-treated group. Overall, these results provide strong evidence that sodium selenite (selenium) can inhibit cell death and tau phosphorylation induced by TNF- $\alpha$ in neuroblastoma cells, through the inhibition GSK-3 $\beta$ and Akt phosphorylation.

\section{Introduction}

Tumor necrosis factor- $\alpha$ (TNF- $\alpha$ ) is a key cytokine that initiates and regulates the cytokine cascade during an inflammatory response in various tissues, including those of the central nervous system (CNS). In the brain tissue of humans, it is secreted from microglia, astrocytes and neurons to maintain homeostatic conditions, but also, to induce pathophysiological responses (1-3). TNF- $\alpha$ binding to receptors and the downstream signaling cascade regulate fundamental processes in brain function, such as the formation and regulation of synapses, regeneration, neurogenesis and maintenance of CNS functions (3). However, the expression of TNF- $\alpha$ in healthy brains is very low, rendering its role under physiological conditions hard to assess (4). In the brain of patients with Alzheimer's disease (AD), TNF- $\alpha$, inflammatory cytokines and neurotoxic molecules are predominantly produced from activated neuronal cells, although most brain-derived TNF- $\alpha$ is synthesized by glial cells (5). TNF- $\alpha$ can also induce a variety of physiological processes including fever, apoptotic cell death, sepsis (through the production of interleukins 1 and 6), cachexia and inflammation, while it inhibits tumorigenesis and viral replication. Therefore, dysregulation of the expression of TNF- $\alpha$ is tightly related to a number of human diseases such as $\mathrm{AD}$, depression, cancer and inflammatory bowel disease (6-9).

A number of studies have suggested novel strategies for the development of medical compounds to cure and/or relieve the symptoms of AD. Among these compounds, selenium has been identified as a candidate agent for the prevention and treatment of AD. Selenite, long been known as an ubiquitous trace compound in nature, has been shown to be essential to animal and human health (10). Sodium selenate was recently found to contribute to the mitigation of pathological symptoms of $\mathrm{AD}$ 
in animal models. Specifically, sodium selenate was shown to reduce tau phosphorylation in SH-SY5Y neuroblastoma cells that stably express human tau carrying the frontotemporal lobar degeneration pathogenic mutation P301L (11). Furthermore, this compound activated the serine-threonine protein phosphatase 2A (PP2A), a key phosphatase implicated in tau protein phosphorylation. Following sodium selenate treatment, TAU441 transgenic mice exhibited reduced levels of phosphorylated and total tau in the hippocampus and amygdala compared to the vehicle-treated group (12). Selenium deficiency promoted the onset and progression of AD pathological phenotypes in the brain of $\mathrm{Tg} 2576$ mice (13). However, few studies have investigated whether selenium treatment can affect tau hyperphosphorylation induced by TNF- $\alpha$ treatment in neuroblastoma cells.

As demonstrated by our data, the increase in cell viability, tau phosphorylation and activity of tau kinases induced by TNF- $\alpha$ is significantly reduced by sodium selenite treatment in neuroblastoma cells, suggesting that sodium selenite treatment can contribute to the recovery of TNF- $\alpha$-induced tau hyperphosphorylation, and ultimately attenuate AD pathological phenotypes, including the accumulation of neurofibrillary tangles (NFT) and memory defects.

\section{Materials and methods}

Cell culture and selenium treatment. SH-SY5Y cells that originated from human neuroblastoma were obtained from the Korean Food and Drug Administration (Osong, Korea). The cell line was maintained for 24-36 h in HyClone ${ }^{\mathrm{TM}}$ RPMI-1640 medium containing $10 \%$ HyClone $^{\mathrm{TM}}$ fetal bovine serum (both from Thermo Fisher Scientific Inc., Waltham, MA, USA), $100 \mathrm{IU} / \mathrm{ml}$ of penicillin and $100 \mu \mathrm{g} / \mathrm{ml}$ of streptomycin. The cells were maintained in a humidified incubator at $37^{\circ} \mathrm{C}$ and $5 \% \mathrm{CO}_{2}$. Sodium selenite $\left(\mathrm{Na}_{2} \mathrm{SeO}_{3}\right)$, hereafter termed as selenite, was purchased from Sigma-Aldrich (cat. no. S5261; St. Louis, MO, USA) and was dissolved in distilled water to a $5 \mu \mathrm{M}$ final concentration.

Experimental groups. Wells in a 96-well plate were randomly divided into two groups. The first group was not treated with Sel or TNF- $\alpha$ and served as the control (non-treated group). The second group was exposed to $25 \mathrm{ng} / \mathrm{ml}$ of TNF- $\alpha$ for $24 \mathrm{~h}$ to induce cell death (TNF- $\alpha$-treated). After $24 \mathrm{~h}$, this group was further divided into four subgroups, a vehicle-treated group and three groups treated with different concentrations of selenite. The first subgroup of cells (TNF- $\alpha+$ vehicle-treated group) received a comparable volume of distilled water, whereas the other three (TNF- $\alpha+$ selenite-treated groups) received different concentrations of selenite $(1.25,2.50$ and $5.00 \mu \mathrm{M}$ ) for $24 \mathrm{~h}$ in order to determine its optimal concentration. From all the above groups, three (non-treated, TNF- $\alpha+$ vehicle and TNF- $\alpha+5.0 \mu \mathrm{M}$ selenite-treated) were retained for further analyses.

Cell viability assay. For the cell viability assay, $\mathrm{SH}-\mathrm{SY} 5 \mathrm{Y}$ cells were seeded in 96 -well plates at a density of $4 \times 10^{4}$ cells $/ 200 \mu \mathrm{l}$ and were grown for $24 \mathrm{~h}$ in a $37^{\circ} \mathrm{C}$ incubator. Upon reaching $70-80 \%$ confluence, cells were exposed to RPMI-1640 medium containing distilled water (vehicle) or TNF- $\alpha$ dissolved in distilled water along with different concentrations of selenite for another $24 \mathrm{~h}$. Cell proliferation was then determined using the tetrazolium compound MTT assay (cat. no. M2128; Sigma-Aldrich). Next, the supernatants from the vehicle or the selenite-treated cells were discarded, $200 \mu \mathrm{l}$ of fresh RPMI-1640 medium and $50 \mu \mathrm{l}$ of MTT solution $(2 \mathrm{mg} / \mathrm{ml}$ in phosphate-buffered saline) were added to each well, and the samples were incubated at $37^{\circ} \mathrm{C}$. Reduction of MTT by viable cells to insoluble purple formazan dye crystals was evaluated in a 220- $\mu \mathrm{l}$ sample recovered after $4 \mathrm{~h}$. The formazan precipitate was dissolved in dimethyl sulphoxide, and the absorbance of the samples was directly read at $570 \mathrm{~nm}$ using a SoftMax Pro 5 spectrophotometer (Molecular Devices, Sunnyvale, CA, USA). The cell number was indirectly evaluated from the absorbance values, allowing to quantify changes in cell proliferation.

Immunofluorescence and 4',6-diamidino-2-phenylindole (DAPI) staining. SH-SY5Y cells were initially seeded in 24-well plates at a density of $1 \times 10^{5}$ cells $/ \mathrm{ml}$, and then grown for $24 \mathrm{~h}$ in a $37^{\circ} \mathrm{C}$ incubator. Upon reaching $70-80 \%$ confluence, cells were exposed to RPMI-1640 medium containing distilled water (vehicle) or selenite dissolved in distilled water for $24 \mathrm{~h}$ after TNF- $\alpha$ treatment. Cells were next fixed with formaldehyde (Junsei Chemical Co. Ltd., Tokyo, Japan) for $1 \mathrm{~h}$ and then permeabilized with $1 \%$ Triton X-100 for $5 \mathrm{~min}$. After blocking with $0.5 \%$ bovine serum albumin for $1 \mathrm{~h}$, cells were incubated overnight at $4^{\circ} \mathrm{C}$ with an antibody targeting the p-tau protein at the Ser404 site (cat. no. sc-12952; Santa Cruz Biotechnology, Inc., Santa Cruz, CA, USA). Cells in each well were then washed with washing buffer $(137 \mathrm{mmol} / 1 \mathrm{NaCl}$, $2.7 \mathrm{mmol} / 1 \mathrm{KCl}, 10 \mathrm{mmol} / 1 \mathrm{Na}_{2} \mathrm{HPO}_{4}, 2 \mathrm{mmol} / 1 \mathrm{KH}_{2} \mathrm{PO}_{4}$ and $0.05 \%$ Tween-20) and incubated at room temperature for $2 \mathrm{~h}$ with fluorescein isothiocyanate-conjugated goat anti-rabbit IgG (Zymed Laboratories Inc., South San Francisco, CA, USA) or with $350.25 \mathrm{mg}$ of Molecular Probes ${ }^{\circledR}$ DAPI (cat. no. D1306; Thermo Fisher Scientific Inc.). Finally, the fluorescence intensity in each cell was detected using the IX71 fluorescent microscope (Olympus, Hamburg, Germany).

Western blot analysis. SH-SY5Y cells were harvested from culture dishes (100 $\mathrm{mm}$ in diameter) following 24-h treatment with distilled water (vehicle) or selenite dissolved in distilled water subsequent to TNF- $\alpha$ treatment. These cell pellets were solubilized in PRO-PREP Protein Extraction Solution (Intron Biotechnology, Inc., Seongnam, Korea) containing $1.0 \mathrm{mM}$ phenylmethylsulfonyl fluoride, $1.0 \mathrm{mM}$ ethylenediamine tetraacetic acid, $1 \mu \mathrm{M}$ Pepstatin $\mathrm{A}, 1 \mu \mathrm{M}$ Leupeptin and $1 \mu \mathrm{M}$ Aprotinin. The supernatant was collected from these lysates subsequent to centrifugation for $10 \mathrm{~min}$ at $10,000 \mathrm{x} \mathrm{g}$ at $4^{\circ} \mathrm{C}$. The protein concentrations were then determined using a BCA Protein Assay Kit (Thermo Fisher Scientific Inc.). Total protein $(30 \mu \mathrm{g})$ isolated from neuroblastoma cell lysate was separated by polyacrylamide gel electrophoresis on a $8-12 \%$ sodium dodecyl sulphate gel for $2 \mathrm{~h}$, and then transferred for $2 \mathrm{~h}$ at $40 \mathrm{~V}$ onto nitrocellulose membranes. Each membrane was incubated overnight at $4^{\circ} \mathrm{C}$ with each of the primary antibodies anti-tau (cat. no. sc-5587; Santa Cruz Biotechnology, Inc.), anti-p-tau (Ser404, cat. no. sc-12952; Santa Cruz Biotechnology, Inc.), anti-glycogen synthase kinase $3 \beta$

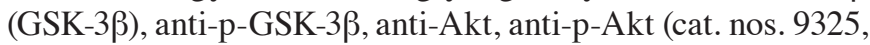


A

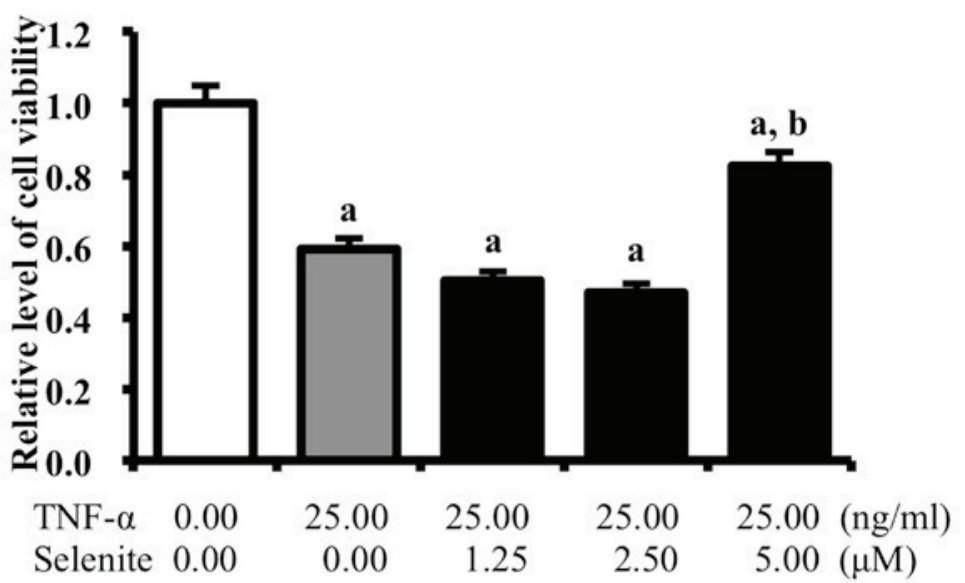

B
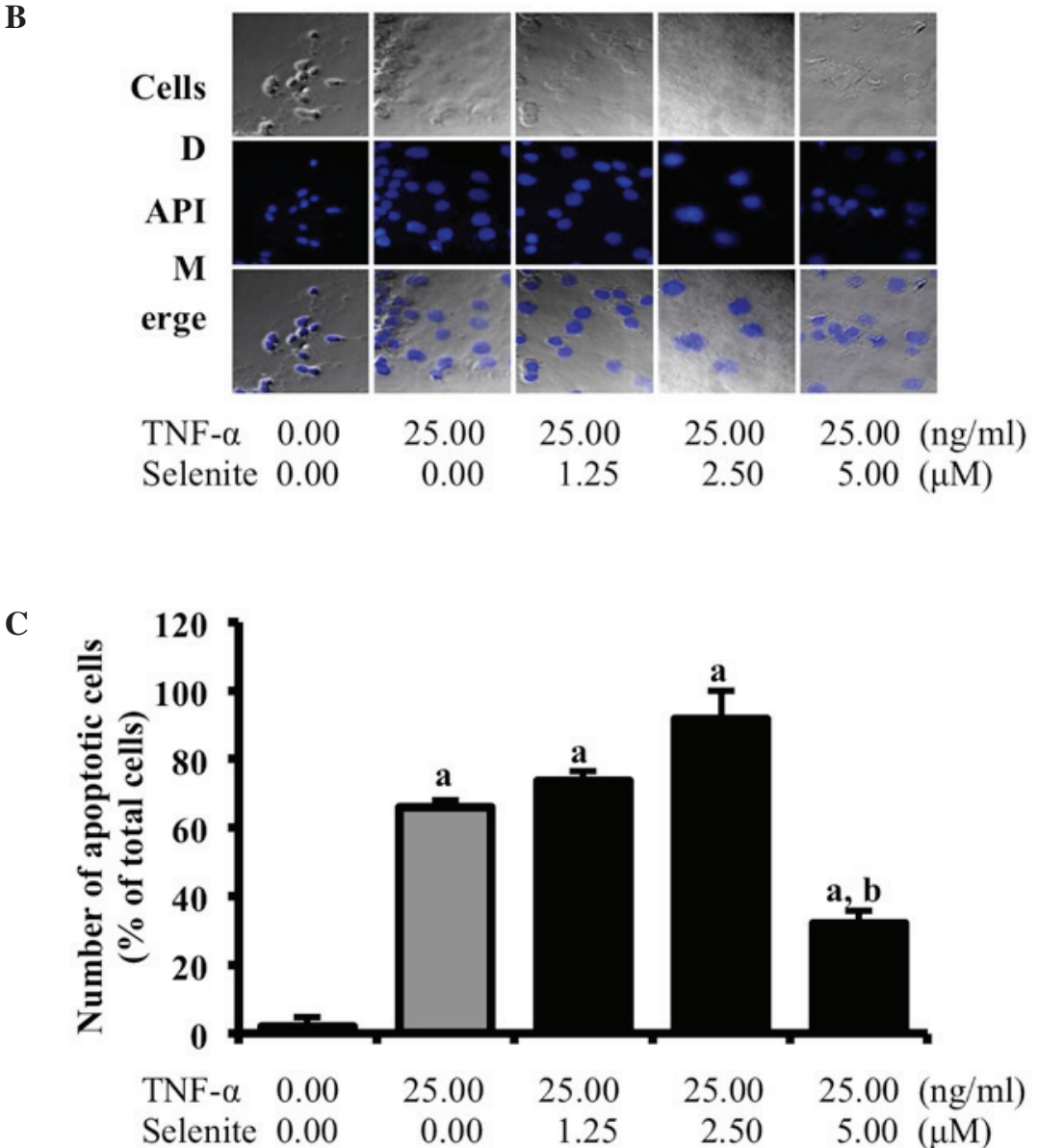

Figure 1. Alterations in cell viability following tumor necrosis factor- $\alpha$ (TNF- $\alpha$ ) and selenite treatment. (A) Relative level of cell viability. Upon treatment with TNF- $\alpha+$ selenite for $24 \mathrm{~h}$, the viability of neuroblastoma cells was measured using the MTT assay. Treatment wirh TNF- $\alpha$ for $24 \mathrm{~h}$ induced death in $40 \%$ of the cells. (B) 4',6-diamidino-2-phenylindole (DAPI) staining. Neuroblastoma cells were treated with TNF- $\alpha+$ selenite for 24 h, fixed with $4 \%$ formaldehyde and stained with DAPI to detect changes in the nucleus. The cellular morphology was observed under a fluorescent microscope (x400 magnification). Triplicate trials per group were performed. (C) Number of apoptotic cells, as evaluated by DAPI staining. Bars denote standard deviation of the mean from three replicates. ${ }^{\text {a }} \mathrm{P}<0.05$ relative to the non-treated group; and ${ }^{\mathrm{b}} \mathrm{P}<0.05$ relative to the TNF- $\alpha$-treated group.

9336, 9272 and 4058 respectively; all from Cell Signaling Technology, Inc., Boston, MA, USA), and anti- $\beta$-actin (cat. no. A5316; Sigma-Aldrich). The membranes were then washed with washing buffer (as in the immunofluorescence assay above) and incubated with horseradish peroxidase-conjugated goat anti-rabbit IgG (dilution, 1:1,000; Zymed Laboratories Inc.) at room temperature for $1 \mathrm{~h}$. The membrane blots were developed using an enhanced chemiluminescence (ECL) Reagent Plus kit (Amersham Pharmacia Biotech, Piscataway, NJ, USA).

Statistical analysis. Non-treated and TNF- $\alpha$-treated groups were compared by a one-way analysis of variance using the software SPSS for Windows (release 10.10, standard version; 
A

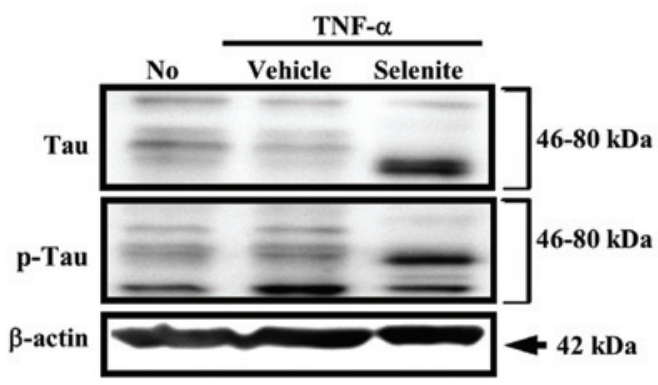

B

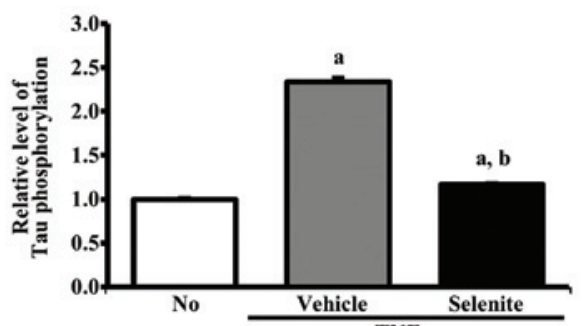

C

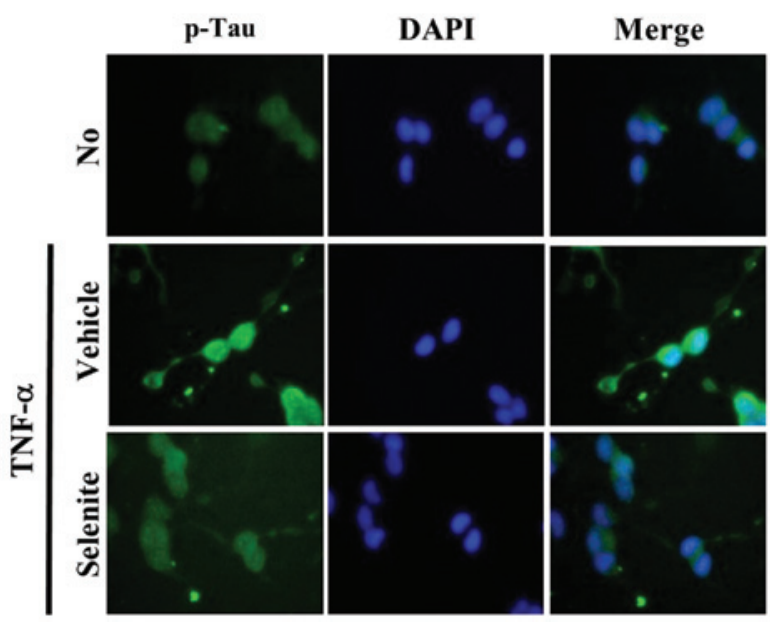

Figure 2. Tau hyperphosphorylation. (A) Western blot analysis. Nitrocellulose membranes with $30 \mu \mathrm{g}$ of total protein from the cell homogenate were incubated with antibody specific to total tau, p-tau (Ser404) and $\beta$-actin, followed by incubation with horseradish peroxidase-conjugated goat anti-rabbit IgG (B) Quantified data from the immunofluorescence assay. Neuroblastoma cells were cotreated with TNF- $\alpha+$ selenite for $24 \mathrm{~h}$ and then fixed with $4 \%$ formaldehyde and stained with a specific antibody targeting the phosphorylated (p)-tau protein, followed by incubation with a secondary antibody coupled to fluorescein. Cells were also stained with DAPI to detect changes in the nucleus. Bars denote standard deviation of the mean from three replicates. ${ }^{\mathrm{a}} \mathrm{P}<0.05$ compared to the non-treated group; and ${ }^{\mathrm{b}} \mathrm{P}<0.05$ compared to the TNF- $\alpha+$ vehicle-treated group. (C) Cellular morphology as observed under a fluorescent microscope (magnification, x400). Vehicle, cells that received a comparable volume of distilled water instead of selenite; and DAPI, 4',6-diamidino-2-phenylindole.

IBM, Armonk, NY, USA). Post hoc tests were performed to identify significant differences between the vehicle and selenite-treated groups. All values were expressed as the mean \pm standard deviation. $\mathrm{P}<0.05$ was considered to indicate a statistically significant difference.

\section{Results}

Selenite treatment-mediated recovery in cell death induced by $T N F-\alpha$. TNF- $\alpha$ treatment induces pathological cell death
$\mathbf{A}$

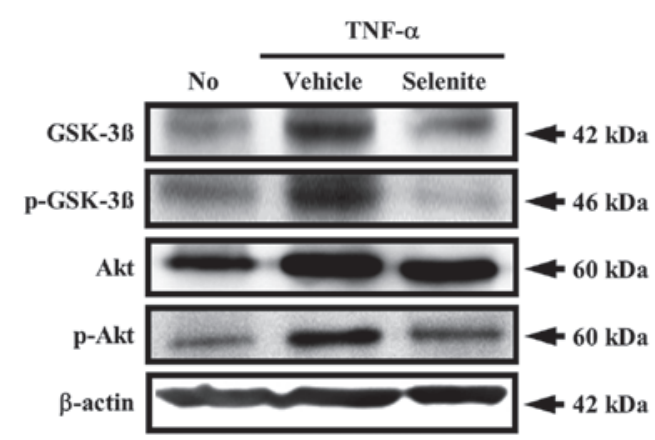

B

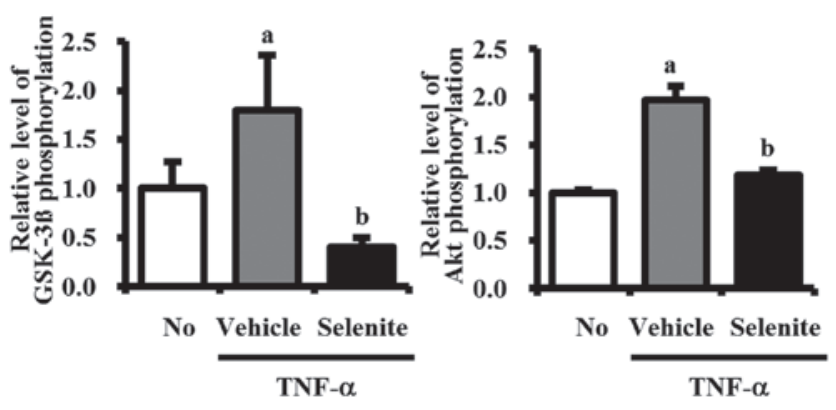

Figure 3. Glycogen synthase kinase $3 \beta$ (GSK-3 $\beta$ ) and Akt phosphorylation. Nitrocellulose membranes with $30 \mu \mathrm{g}$ of protein from the cell homogenate

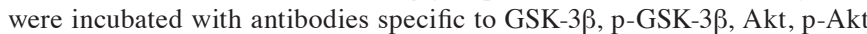
and $\beta$-actin, followed by incubation with horseradish peroxidase-conjugated goat anti-rabbit IgG. (A) Representative western blot image, acquired and processed with the Kodak electrophoresis documentation and analysis system 120. (B) Quantified protein band densities. Bars denote standard deviation of the mean from three replicates. ${ }^{\text {a }} \mathrm{P}<0.05$ compared to the non-treated group; and ${ }^{\mathrm{b}} \mathrm{P}<0.05$ compared to the $\mathrm{TNF}-\alpha+\mathrm{vehicle-treated} \mathrm{group.} \mathrm{Vehicle,}$ cells that received a comparable volume of distilled water instead of selenite.

(necrosis) and physiological gene-directed cell death (apoptosis) in various cells (14). We therefore examined whether selenite treatment can prevent neuronal cell death induced by TNF- $\alpha$ treatment. For this purpose, cell viability was measured in neuroblastoma cells treated with different concentrations of selenite using the MTT assay and DAPI staining analysis. TNF- $\alpha$-treated cells showed a low level of viability compared to non-treated cells. Cell viability was significantly increased in cells cotreated with TNF- $\alpha$ and high concentrations of selenite, but not when lower concentrations of selenite were used (Fig. 1A). Similar results were observed with DAPI staining analysis. Specifically, a higher number of apoptotic cells with fragmented or compacted nuclei was detected in TNF- $\alpha+$ vehicle-treated cells relative to the non-treated group, whereas a reduced number of apoptotic cells was observed in the TNF- $\alpha+$ selenite-treated cells relative to TNF- $\alpha+$ vehicle-treated cells (Fig. 1B and C). However, there was not a significant number of apoptotic cells identified in SH-SY5Y normal cells (Data not shown). Taken together, our findings indicate that selenite treatment may inhibit the cell death induced by TNF- $\alpha$ treatment in neuroblastoma cells.

Effects of selenite treatment on tau hyperphosphorylation. To determine whether selenite treatment can alter tau hyperphosphorylation, the levels of total tau and phosphorylated-tau at Ser404 were measured in the 
TNF- $\alpha+$ selenite-treated group. Multiple tau isoforms were observed in the 46-80 kDa range of molecular weight (Fig. 2A). However, it is very difficult to correspond a specific band as six isoforms, as tau is subject to a variety of post-translational modifications including phosphorylation, polyubiquitination and glycation (15). The total level of tau phosphorylation was significantly higher in the TNF- $\alpha+$ vehicle-treated compared to the non-treated group. Following selenite treatment, the level of p-tau was significantly decreased, while that of unphosphorylated tau was markedly increased. Notably, the band intensity of the tau isoform 46-50 kDa decreased three-fold in the TNF- $\alpha+$ selenite-treated relative to the TNF- $\alpha+$ vehicle-treated group, while the band intensity of tau isoform with 65-70 kDa was enhanced in the same group. The level of $\beta$-actin, used as an endogenous control, remained constant in all groups (Fig. 2A and B).

To determine whether hyperphosphorylation of the tau protein induced by TNF- $\alpha$ is involved in cell death, the cells were stained with the anti-p-tau antibody, and fluorescence intensity was observed under a fluorescence microscope. The fluorescence intensity of the $\mathrm{p}$-tau protein in the TNF- $\alpha+$ vehicle-treated group was higher than that observed in non-treated cells, while a lower level of p-tau intensity was observed in TNF- $\alpha+$ selenite-treated cells compared to TNF- $\alpha+$ vehicle-treated cells, confirmed by repeated experiments. Furthermore, a high number of cells containing fragmented or compacted nuclei was detected in TNF- $\alpha+$ vehicle-treated cells exhibiting a high intensity of p-tau when compared to the non-treated group. Following TNF- $\alpha+$ selenite treatment, the number of apoptotic cells with fragmented or compacted nuclei was reduced (Fig. 2C). Overall, these results suggest that the inhibition of tau hyperphosphorylation observed after selenite treatment may associate with the inhibition of apoptotic cell death in neuroblastoma cells.

Effects of selenite treatment on GSK-3 $\beta$ and Akt phosphorylation. The tau protein is a phosphoprotein that potentially has 80 serine/threonine and 5 tyrosine phosphorylation sites (15). Phosphorylation of tau was shown to be regulated by kinases, such as GSK-3 $\beta$ and Akt $(15,16)$. To determine whether selenite treatment is accompanied by downregulation of the activity of these kinases, the phosphorylation level of GSK-3 $\beta$ and Akt was measured. The phosphorylation level of GSK-3 $\beta$ was higher in the TNF- $\alpha+$ vehicle-treated group compared to the non-treated group, although the total level of GSK-3 $\beta$ also increased in response to TNF- $\alpha$ treatment. However, the level of p-GSK-3 $\beta$ was markedly decreased in the TNF- $\alpha+$ selenite-treated compared to the TNF- $\alpha+$ vehicle-treated group. Alterations in the phosphorylation level of Akt were very similar to those of GSK-3 $\beta$. Specifically, the phosphorylation level of Akt was reduced down to a level similar of that of the non-treated group upon TNF- $\alpha+$ selenite treatment (Fig. 3A and B). Taken together, these results indicate that selenite treatment may inhibit tau phosphorylation through inhibition of GSK-3 $\beta$ and Akt phosphorylation.

\section{Discussion}

The selenium content of healthy adult humans can vary widely, ranging from 3 to $20 \mathrm{mg}$, based on the influence of the natural environment on the selenium content of soils, crops and human tissues (17). Furthermore, selenium is widely distributed in several tissues of the human body. Approximately $30 \%$ of tissue selenium is found in the liver, $15 \%$ in the kidney, $30 \%$ in muscles and $10 \%$ in the blood serum (17). In addition, the effects of different selenium concentrations on tau phosphorylation have been shown to slightly differ among studies. In SH-SY5Y neuroblastoma cells overexpressing human tau (P301L mutation), the phosphorylation level of tau at Ser422 was markedly reduced in the $10-1,000 \mu \mathrm{M}$ selenate-treated group, while it was not altered in response to treatment with $<10 \mu \mathrm{M}$ selenite (11). However, analysis of the activity of the serine-threonine phosphatase PP2A revealed a significant effect on tau phosphorylation in fresh complete growth medium containing $100 \mu \mathrm{M}$ sodium selenate (12). In this study, the cell viability and tau hyperphosphorylation were significantly altered in response to treatment with $5 \mu \mathrm{M}$ selenite. These results greatly differ from those of previous studies, in which tau phosphorylation was affected by high concentrations of selenate. We argue that this difference is due to variations in treatment conditions, e.g. on the duration of the treatment, and in the structure of the tested compounds.

Although selenium is an essential trace element, it is toxic to humans if consumed in excess. A follow-up study of five Chinese patients suggested that selenosis can be induced by exceeding the tolerable upper intake level of 400-800 $\mu \mathrm{g}$ /day (18). In addition, serum selenium concentrations are categorized by the determination of caused symptoms in the patients as follows: i) 400-30,000 $\mu \mathrm{g} / 1$, acute toxicity; ii) $500-1,400 \mu \mathrm{g} / 1$, chronic toxicity; and iii) $<1,400 \mu \mathrm{g} / 1$, no toxicity (19). In neuroblastoma cells overexpressing the human tau mutant (P301L) protein, two forms of selenium were found to exert different cytotoxic effects. Specifically, selenate cytotoxicity observed above a dose of $1 \mathrm{mM}$, while selenite was toxic only above a dose of $10 \mu \mathrm{M}$. However, selenite showed no cytotoxicity below a dose of $10 \mu \mathrm{M}$ (11). In our study, selenite did not induce any specific toxicity at $<5 \mu \mathrm{M}$, although cell viability was not significantly decreased at $2.5 \mu \mathrm{M}$ (data not shown). The results of the present study are very similar with those of a previous study although above data was not measured toxicity at a dose of $5 \mu \mathrm{M}$.

Sodium selenate has been reported to reduce tau phosphorylation both in vitro and in vivo. For example, selenate-treated cells showed a dose-dependent reduction in tau phosphorylation at multiple phosphorylation sites, including pS422, 12E8 and PHF-1 (11). In addition, the same study showed that two independent tau transgenic mice models with NFT pathology exhibit a significant reduction in tau phosphorylation and complete abrogation of NFT formation after chronic oral treatment with sodium selenate (11). Acute treatment with sodium selenate rapidly reduced tau phosphorylation in either neuroblastoma cells or healthy aged mice, through regulation of PP2A, while it induced improved spatial learning and memory and decreased tau phosphorylation in TAU441 transgenic mice (12). The present study is the first to demonstrate the effects of sodium selenite on tau phosphorylation induced by TNF- $\alpha$ treatment. Specifically, cells treated with TNF- $\alpha$ and selenite recovered to the level of non-treated cells in terms of cell viability, tau hyperphosphorylation and activity of tau kinases. These results are in agreement with those of previous 
studies (12), which suggested that sodium selenate may mitigate tau phosphorylation and specifically activate PP2A in neuroblastoma cells and transgenic mice.

Taken together, our results showed that sodium selenite is associated with mitigation of TNF- $\alpha$-induced pathogenesis, by inhibiting cell death, tau hyperphosphorylation and activation of kinases in neuroblastoma cells. Our findings suggest that sodium selenite may play a crucial role in the regulation of tau phosphorylation via modulation of the activity of tau kinases, and it thus may serve as a new therapeutic agent in AD treatment by modulating tau phosphorylation.

\section{Acknowledgements}

This study was supported by the 2013 Specialization Project Research Grant funded by the Pusan National University.

\section{References}

1. Hanisch UK: Microglia as a source and target of cytokines. Glia 40: 140-155, 2002.

2. Klintworth H, Garden G and Xia Z: Rotenone and paraquat do not directly activate microglia or induce inflammatory cytokine release. Neurosci Lett 462: 1-5, 2009.

3. Montgomery SL and Bowers WJ: Tumor necrosis factor-alpha and the roles it plays in homeostatic and degenerative processes within the central nervous system. J Neuroimmune Pharmacol 7: 42-59, 2012.

4. Rubio-Perez JM and Morillas-Ruiz JM: A review: inflammatory process in Alzheimer's disease, role of cytokines. ScientificWorldJournal 2012: 756357, 2012.

5. Breder CD, Tsujimoto M, Terano Y, Scott DW and Saper CB: Distribution and characterization of tumor necrosis factor- $\alpha$-like immunoreactivity in the murine central nervous system. J Comp Neurol 337: 543-567, 1993.

6. Swardfager W, Lanctot K, Rothenburg L, Wong A, Cappell J and Herrmann N: A meta-analysis of cytokines in Alzheimer's disease. Biol Psychiatry 68: 930-941, 2010.
7. Dowlati Y, Herrmann N, Swardfager W, Liu H, Sham L, Reim EK and Lanctot KL: A meta-analysis of cytokines in major depression. Biol Psychiatry 67: 446-457, 2010.

8. Locksley RM, Killeen $\mathrm{N}$ and Lenardo MJ: The TNF and TNF receptor superfamilies: integrating mammalian biology. Cell 104: 487-501, 2001

9. Brynskov J, Foegh P, Pedersen G, Ellervik C, Kirkegaard T, Bingham A and Saermark T: Tumour necrosis factor alpha converting enzyme (TACE) activity in the colonic mucosa of patients with inflammatory bowel disease. Gut 51: 37-43, 2002.

10. Wilber CG: Toxicology of selenium: a review. Clin Toxicol 17: 171-230, 1980.

11. van Eersel J, Ke YD, Liu X, Delerue F, Kril JJ, Gotz J and Ittner LM: Sodium selenate mitigates tau pathology, neurodegeneration, and functional deficits in Alzheimer's disease models. Proc Natl Acad Sci USA 107: 13888-13893, 2010.

12. Corcoran NM, Martin D, Hutter-Paier B, Windisch M, Nguyen T, Nheu L, Sundstrom LE, Costello AJ and Hovens CM: Sodium selenate specifically activates PP2A phosphatase, dephosphorylates tau and reverses memory deficits in an Alzheimer's disease model. J Clin Neurosci 17: 1025-1033, 2010.

13. Haratake M, Yoshida S, Mandai M, Fuchigami $T$ and Nakayama M: Elevated amyloid- $\beta$ plaque deposition in dietary selenium-deficient Tg2576 transgenic mice. Metallomics 5: 479-483, 2013.

14. Sarraf CE: Tumor necrosis factor and cell death in tumors (Review). Int J Oncol 5: 1333-1339, 1994.

15. Wang JZ, Xia YY, Grundke-Iqbal I and Iqbal K: Abnormal hyperphosphorylation of tau: sites, regulation, and molecular mechanism of neurofibrillary degeneration. J Alzheimers Dis 33 (Suppl 1): S123-139, 2013.

16. Chung ES, Bok E, Sohn S, Lee YD, Baik HH and Jin BK: GT1b-induced neurotoxicity is mediated by the Akt/GSK-3/tau signaling pathway but not caspase-3 in mesencephalic dopaminergic neurons. BMC Neurosci 11: 74, 2010.

17. Food and Agriculture Organization of the United Nations (FAO)/ World Health Organization (WHO): Human vitamin and mineral requirements: report of a Joint $\mathrm{FAO} / \mathrm{WHO}$ expert consultation Bangkok, Thailand. FAO, Rome, Italy, pp235-255, 2002.

18. Yang G and Zhou R: Further observations on the human maximum safe dietary selenium intake in a seleniferous area of China. J Trace Elem Electrolytes Health Dis 8: 159-165, 1994.

19. Nuttall KL: Evaluating selenium poisoning. Ann Clin Lab Sci 36: 409-420, 2006. 